\title{
Revisão: dinâmica de Haroldo de Campos na Cultura Brasileira
}

Horácio Costa | USP

Resumo: Revisão da trajetória de Haroldo de Campos através da poesia concreta e da cultura nacional. Palavras-chave: Haroldo de Campos, cultura brasileira.

Mais de quarenta anos após a publicação de Auto do Possesso (1949) e trinta e cinco da irrupção do Movimento da Poesia Concreta, a trajetória de Haroldo de Campos permite interpretações panorâmicas, aceita novos olhares críticos, demanda cortes para ser avaliada. A sua grande produção, algo protéica e multiforme, seja como poesia, ensaio, tradução, ideologia ou animação cultural, hoje cravada no centro da cultura brasileira, presta-se a olhares em todos os sentidos, aceita as mais variadas denominações e responde a diferentes sinais interpretativos. Além disso, sua obra, que se propôs e se propõe aberta, recusa um horizonte interpretativo único, uma definição redutora, não só por se encontrar in progress, mas também por apresentar um valor constitutivo central: o de rejeitar, em princípio, qualquer esquema analítico cabal ou verocêntrico, já que está, na sua totalidade, completamente estruturada pelo vetor crítico, por natureza dinâmico e transformador. 
Em poucas palavras, a qualquer tentativa de revisão panorâmica corresponde, inversamente, uma obra não só rica no seu inventário, mas também multifacetada na sua figuração. Fazer um panorama, portanto, implica um risco: o de desenhar um falso perfil genérico num corpo com movimento próprio, que não aconselha tentativa alguma no sentido de estabilização interpretativa. Isto posto, a revisão parcial da obra de Haroldo de Campos que segue está condicionada pela consciência dessa perigosa situação paradoxal e não se pretende mais do que um ensaio no duplo sentido do termo: não só uma passagem crítica, mas também um gesto intelectual feito por tentativas que, por não abolir o azar, acaba por se revelar como jogo entre aquele que ensaia e o acaso da interpretação.

A múltipla presença haroldiana no contexto brasileiro contemporâneo caracteriza-se por três valores éticos inter-relacionados, vinculados a diferentes vertentes discursivas de sua obra e que, também, conformam as bases de uma linha de atuação intelectual, de um projeto cultural de grande fôlego. Estes valores incluem a conciliação em relação à sua geração no contexto da poesia brasileira a partir de 1922, a logodescentralização referida à sua atividade como crítico do logos nacionalformativista na historiografia da literatura brasileira e a dinamização cultural, em relação aos diálogos que o poeta manteve, ao longo da sua carreira, com outras áreas da expressão artística no Brasil. Neste trabalho, abordarei, principalmente, o primeiro desses tópicos; em relação ao segundo, sobre o qual escrevi um ensaio, ${ }^{1}$ aludirei, no seu momento, de forma complementar.

Ao longo da sua obra, Haroldo de Campos adotou com clareza duas posições, a vanguardista e a pós-vanguardista - ou, segundo o poeta, "pós-utópica", termo que ele prefere a "pós-moderna"

1. Ver: "Haroldo de Campos: seguimiento de una irreprochable trayectoria". México, Vuelta № 163 (junio de 1990).

2. $C f$. a conferência "Da poesia concreta a Galaxias y Finismundo: cuarenta anos de atividade poética no Brasil", apresentada na "Cátedra Guimarães Rosa de Estudios Luso-Brasileños" da Facultad de Filosofía y Letras de la Universidad Nacional Autónoma de México (UNAM), no dia 6 de março de 1991 e publicada na revista Vuelta N0 177 (Agosto de 1991; tradução de Carmen Salas e Rodolfo Mata), em que Haroldo de Campos diz: "[...] imaginei Finismundo como um poema 'pós-utópico', expresão que prefiro antes que o conceito já gasto e equívoco de "pós-moderno". 
no âmbito da cultura brasileira e com as reservas óbvias, as posturas estéticas e vivenciais das duas primeiras gerações modernistas. Como é sabido, elas foram as responsáveis pela implantação do discurso da modernidade estética internacional no Brasil, ao inaugurar, com a sua apropriação criativa desse discurso, toda uma mecânica de produção artística nacional que as apresenta, aos nossos olhos, como fundadoras de todo o discurso posterior da cultura brasileira.

Como já tive a oportunidade de explicar num ensaio publicado no México, "Panorama de la poesía brasileña en el siglo XX", considero que o momento geralmente conhecido como "heróico" da primeira geração modernista - que corresponde ao período entre a Semana de Arte de São Paulo, em 1922, e a crise nacional de 1920/30 -, movido por uma tendência visceral à transformação e que tão profundas repercussões teve na vida intelectual do Brasil, representa, apesar das características formais vanguardistas de muitos dos produtos literários que ali surgiram, uma etapa introdutória e, até, anterior à modernidade estética plena. À fúria ou paixão iconoclasta de Mário de Andrade, que escreve o "Prefácio Interessantíssimo" (em Paulicéia Desvairada, 1921), ou de Oswald de Andrade "vanguardista", que redige os manifestos fundamentais "Pau-Brasil" e "Antropofagia", na década de 1920, que deram como resultado a criação exemplar de uma plataforma para a expansão de uma arte nacional de vanguarda, seguem, entre os jovens que se afirmam no quadro da geração seguinte, duas vozes menos virulentas na sua dicção e menos programadas para levar adiante um projeto cultural radicalmente transformador: o reticente Carlos Drummond de Andrade e o atípico (em relação ao quadro da época), surreal-metafísico, Murilo Mendes.

O traço comum que aqui me interessa sublinhar entre estes últimos poetas é a sua afirmação-superação de algumas posturas éticas, que a geração "heróica" do Modernismo tinha adotado no seu combate contra a cultura brasileira oficial. Ambos são, naquele momento inicial das suas carreiras, prolongações críticas, e não por isso menos simpáticas, da obra inseminadora dos seus antecessores. Sua grande contribuição ao Modernismo é, como apontei acima, uma mudança de dicção na qual percebemos alteração do tonus "antagonista" e "ativista" - utilizo aqui a conhecida terminologia de Renato Poggioli no seu clássico estudo "The theory of the Avant-Garde" (1968) que caracterizou nossa primeira vanguarda. ${ }^{4}$

3. "Panorama de la poesía brasileña en el siglo XX". México, EE y L. - UNAM, colección "Cuadernos de Docencia", 1990; 30 p. 
O Drummond gauche e ensimesmado, que problematiza o impulso e a escrita poética em "Busca da Poesia" (1945), obra em que recomenda ao leitor-poeta "penetrar surdamente no reino das palavras" que "transformam-se em desprezo", já em "Hino Nacional" (de Brejo das Almas, 1934) diz que "necessitamos olvidar o Brasil”, porque

Nosso Brasil no outro mundo. Este não é o Brasil.

Nenhum Brasil existe. E acaso existirão os brasileiros?

contrapõe-se, deste modo, à dicção afirmativa, um tanto eufórica e "nacional" do primeiro Modernismo, especialmente àquela da obra do Mário de Andrade "heróico", seu evidente mestre e primeiro interlocutor. ${ }^{5}$ Em sua obra poética posterior, Mário de Andrade persistirá na utilização de um vocabulário e de uma sensibilidade "nacionais", perseguindo assim a concreção de um sempre mirífico projeto de escrever numa língua poética tipicamente brasileira. Por outro lado, seu desencantamento com os caminhos da cultura nacional, depois de 1930, fica evidente no poema tardio "Meditação sobre o Tietê", escrito em 1944-45, no qual o ex-poeta "futurista" desconsoladamente se pergunta o que havia sucedido com o espírito das "Juvenilidades Auriverdes", espírito anarquizante e libertador que regia sua já mencionada obra de estréia, Paulicéia Desvairada, seu ousado "oratório profano", "As enfibraturas do Ipiranga". Também, na sua famosa conferência-testamento de 1942, "O movimento modernista”, Mário

4. Cf.: Renato Poggioli, The theory of the Avant-Garde. Harvard University Press, 1968 (1a ed.). Ver em especial os capítulos I ("The concept of the AvantGarde") e II ("The concept of a Movement").

5. Ver, nesse sentido, a correspondência entre Mário de Andrade e Drummond, anterior à publicação de Alguma poesia, primeira obra de Drummond (1930); ver também o elogioso artigo "A poesia em 1930", no qual, já em 1931, Mário de Andrade ressalta a importância do jovem Drummond no panorama da poesia brasileira desse momento (esse ensaio foi reunido em Aspectos da literatura brasileira, São Paulo, Martins, 1931, e republicado em Carlos Drummond de Andrade - Fortuna crítica; org. Sônia Brayner. Rio de Janeiro, Civilização Brasileira, 1978). Também, para se compreender mais amplamente a importância da personalidade de Mário de Andrade para Drummond, ler o poema "Mário de Andrade desce aos infernos", tributo que Drummond dedica a seu mestre quando de sua morte, incluído em A Rosa do Povo (1945). 
de Andrade dirá que os fogosos participantes de 22 não eram mais que "os filhos finais de uma civilização que acabou" e acrescenta que "sabe-se que o cultivo delirante do prazer individual arrecada as forças dos homens sempre que uma idade morre".

Por sua vez, o Murilo Mendes que em seu primeiro livro Poemas (1929) descreve a si mesmo como "a luta entre um homem acabado / e um outro homem que está andando no ar" (no poema "A luta"), é o que em "Post-Poema" (de Poesia Liberdade, 1945), dirá:

Não se trata de ser ou não ser,

Trata-se de ser e não ser. ${ }^{8}$

Esses são versos cuja simplicidade contrasta, na sua indiferenciação radical, com a nota introdutória que Oswald de Andrade antepõe ao texto do romance Serafim Ponte Grande (1933), na qual o ideólogo da mais promissora vertente modernista se confessa um "palhaço da burguesia" e classifica seu "grande não-livro de fragmentos de livros" - segundo a certeira definição de Haroldo de Campos sobre Serafim..." - como um "necrológio da burguesia" e "epitáfio" do que ele, Oswald, que agora se propõe a ser, um "frac

6. Para fazer mais explícita a amargura de Mário de Andrade, transcrevo a referida passagem de "Meditação sobre o Tietê":

Qué-de as Juvenilidades Auriverdes!

Eu tenho mêdo... meu coração está pequeno, tanta

Essa demagogia, tamanha,

Que eu tenho mêdo de abraçar os inimigos,

Em busca apenas dum sabor,

Em busca dum olhar,

Um sabor, um olhar, uma certeza... (...)

(Ver Mário de Andrade: Poesias Completas. São Paulo, Martins, 1972 [3. ed.];

"Meditação sobre o Tietê", p. 305-314; cit. p. 309).

7. Mário de Andrade: "El movimiento modernista". Publicado em Arte y arquitectura del modernismo brasileño, Caracas, Biblioteca Ayacucho, 1978; p. 181-203 (cit. p. 201). Trad. Santiago Kovadloff.

8. Ver "A Luta" em Poemas e Bumba-meu Poeta; Rio de Janeiro, Nova Fronteira, 1989 [reedição organizada e comentada por Luciana Stegagno-Picchio]; p. 58; e "Pós-Poema" em Antologia Poética; Rio de Janeiro, Fontana, 1976; p. 90. 
de aço da Revolução Proletária”, fora durante o período inicial do Modernismo. Expressando uma tendência exacerbada à autocrítica semelhante à passagem antes citada de Mário de Andrade, a verve de Oswald está bem caracterizada num trecho da sua nota introdutória, na qual o ex-poeta-"antropófago" demonstra um imenso rancor contra seu passado literário, como se estendesse um contundente atestado de óbito na direção da empresa modernista:

\begin{abstract}
O movimento modernista, culminado no sarampão antropofágico, parecia indicar um fenômeno avançado. São Paulo possuía um poderoso parque industrial. Quem sabe se a alta do café não ia colocar a literatura nova-rica da semicolônia ao lado dos custosos surrealismos imperialistas? ${ }^{10}$
\end{abstract}

Os conflitos político-ideológicos e a mea-culpa de Oswald de Andrade, apontados nessas passagens, estiveram presentes em sua obra até a retomada dos explosivos conteúdos da Antropofagia nos ensaios "A crise da filosofia messiânica" e "A marcha das utopias", escritos pouco tempo antes da sua morte, no começo da década de $50 .^{11}$ Seus conflitos estão em consonância com um desencantamento nostálgico e com a menos espetacular mea-culpa de Mário de Andrade, traços que marcaram de forma intermitente sua obra até o final, apesar de momentos de maior objetivação crítica. Um exemplo desses momentos mais objetivos é percebido na já mencionada conferênciatestamento, quando o poeta diz que "o direito permanente à pesquisa estética, a atualização da inteligência artística brasileira e a estabilização de uma consciência criadora nacional" constituíram o principal legado do modernismo. ${ }^{12}$

Mesmo levando em conta os fatores históricos da retração econômica e da radicalização política internacional anteriores à Segunda Guerra Mundial, e apesar das evidentes diferenças de temperamento entre os dois principais nomes

9. Haroldo de Campos: "Serafim: um grande não livro", prólogo da 6a ed. de Serafim Ponte Grande, in Oswald de Andrade: Obras completas (Vol. II Memórias sentimentais de João Miramar [7a ed.] e Serafim Ponte Grande [6a ed.], Rio de Janeiro, Civilização Brasileira, 1980; p. 101-127. p. 107.

10. In: Oswald de Andrade: op. cit. Nota introdutória a Serafim Ponte Grande, cit., p. 131-133.

11. Oswald de Andrade: A utopia antropofágica; São Paulo, Globo, 1990 (arte da reedição das Obras Completas de Oswald de Andrade). "A crise da filosofia messiânica”, pp. 101-155; "A marcha das utopias", p. 161-210.

12. Mário de Andrade: "El movimiento modernista", cit.; p. 191. 
de nosso primeiro modernismo, a ênfase na cisão entre o momento "heróico" e o ulterior, comum tanto a Mário quanto a Oswald de Andrade, aponta para um mesmo sentido ético: a irreconciabilidade entre os momentos vanguardista e pósvanguardista. De forma menos nítida, assinala também a divisão entre o indivíduo programático e o indivíduo crítico, sutil esquizofrenia vivencial e cultural que não vemos nem no Drummond reticente, nem no atípico surreal-metafísico Murilo Mendes, que nasceram, em termos literários, tanto menos doutrinários quanto mais imbuídos de relativismo.

O papel da segunda geração modernista no Brasil foi, portanto, continuar o vetor de libertação da primeira, incorporando plenamente à sua produção textual a herança daquela, acrescentando nisso, no entanto, uma especificidade tonal, que hoje se revela necessária para a própria sobrevivência do Modernismo como um movimento de grande fôlego. Sem a intervenção desta geração estabilizadora, talvez o enorme esforço criador do momento "heróico" teria se diluído tragicamente, como aconteceu em muitos lugares. ${ }^{13}$ Conforme indiquei anteriormente, agindo no sentido de transformar aquilo que poderia ter sido um momento num sistema literário, a geração de 1930 completa o trânsito entre Modernismo e Modernidade.

Essa passagem afortunada, no entanto, poderia ter se esvaído se a miopia estético-ideológica e a incúria parricida da geração de 1945 , excetuando-se João Cabral de Melo Neto, tivessem se afirmado no palco da poesia brasileira no pós-Segunda Guerra Mundial. A geração que, segundo a cronologia, é a terceira que advém depois da eclosão do Modernismo revelou-se um agrupamento crepuscular, demasiado atraído pela segurança que lhe garantia utilizar-se irreflexivamente de formas poéticas tradicionais e excessivamente permeáveis às correntes existencialistas contemporâneas. Uma geração como essa, extremamente autocomplacente, ligada mais à sua promoção narcísica que à problematização do fazer poético e que, além disso, contraria considerar criticamente a sua incumbência dentro do quadro evolutivo da literatura à qual está arraigada, convida, pode se dizer que de forma natural, à contestação, ou ainda, ao repúdio, por aqueles que a acompanham.

13. Penso, sobretudo, no "Estridentismo" mexicano, contemporâneo do Modernismo brasileiro, que teve um efeito reduzido na vida intelectual e artística do México e que hoje, pelo menos no âmbito da crítica literária mexicana, se vê relegado a uma posição de segunda classe, tratado mais como uma referência historiográfica que como uma força cultural fertilizadora. 
Nesse sentido, o movimento da poesia concreta, que se formaliza aproximadamente dez anos depois da geração de 1945, ainda que reúna em termos cronológicos a quarta geração posterior à de 1922, representa a terceira afirmação do movimento modernista e a sua segunda reciclagem no panorama da poesia brasileira. Essa afirmação, essa reciclagem só se opõe, nos aspectos mais básicos do discurso literário, ao esvaziamento do brio modernista que coordenara a atuação da geração de 45. Reclamando como sua a herança modernista, se apropriando dela segundo as suas necessidades trinta anos depois do movimento de 1922, os poetas concretos da década de 1950, observados quatro décadas depois de ocuparem protagonicamente a linha de frente da cultura brasileira, permitem hoje identificar, no seu resgate, um arco entre gerações que, com suas variantes e evidentes pontos de contato, constitui aquilo que poderíamos chamar de tradição moderna brasileira. Esta tradição estaria formada por sístoles e diástoles que se associam à implantação de discursos de vanguarda e sua conseqüente estabilização, mecânica que não difere fundamentalmente do padrão internacional de recepção dos movimentos de vanguarda num palco cultural qualquer.

Excederia os limites deste ensaio detalhar a oposição do movimento da poesia concreta em relação aos membros da geração de 45, suas variantes e pontos de contato com as duas primeiras gerações modernistas. Numa conferência-balanço da sua trajetória poética pronunciada, não faz muito tempo, no México, "De la poesía concreta a Galaxias y Finismundo: cuarenta años de actividad poética en Brasil", Haroldo de Campos, falando também por Décio Pignatari e Augusto de Campos, ao se referir ao momento anterior à formalização da poesia concreta nos primeiros anos de 1950 - a "difícil alvorada", no dizer de Sérgio Buarque de Hollanda - resume da seguinte forma o primeiro desses tópicos:

(...) O ideário dos poetas de 45, seu anti-experimentalismo, sua inclinação ao decorum e o comedimento, sua preocupação pelo clima do poema (onde tudo fosse harmonia e consonância) era algo que não nos atraía a nós três, poetas novíssimos, que admirávamos a sintaxe subversiva e o léxico enigmático de Mallarmé; que estávamos descobrindo o método ideogramático dos Cantos de Ezra Pound; que líamos com entusiasmo ao Apollinaire de Lettre-Océan y dos Calligrammes e ao Lorca das metáforas dissonantes do Poeta en Nueva York. ${ }^{14}$ 
Mais adiante, no mesmo texto, Haroldo de Campos se refere também ao segundo item antes apontado, dizendo que, com o surgimento da poesia concreta em 1956, ele e seus jovens companheiros retomavam "o fio condutor da vanguarda experimental dos anos vinte, interrompido pela ancoragem neoparnasiana da conservadora geração de 45".

Frente à geração de 22, o movimento da poesia concreta é tanto experimental quanto militante; como aquela, esta significa um esforço bem sucedido de aggiornamento do processo criativo brasileiro. Este aggiornamento, no entanto, apresenta um valor diferente ao propiciado pela empresa modernista de 1922: já não envolve a importação de informações internacionais, mas a criação e exportação de conteúdos e de uma linguagem próprias, nacionais na sua radicação, mas longe do horizonte ideológico nacionalista - o que revela a definitiva apropriação, por parte da inteligência criativa brasileira, de um projeto nacional aberto. Combatendo o nacionalismo "ontológico" em favor de um nacionalismo "modal" - terminologia de Haroldo de Campos ${ }^{15}$-, fato que se torna mais digno de elogio quando consideramos que esta abertura programática ocorre no momento de radicalização políticoideológica internacional da guerra fria, a poesia concreta põe em prática o axioma oswaldiano de criar uma "poesia de exportação", afinada com a atualidade estética internacional. Em termos do nosso processo literário, o momento "heróico", antagonista-ativista, da poesia concreta é, graças a este fator, sob um duplo aspecto, "pós-modernista": porque se inspira no espírito de luta do modernismo da primeira hora, e porque leva à prática um vetor desenhado, mas não totalmente realizado, pelo projeto estético-ideológico modernista. Assim, o rigor intelectual e expressivo que projetam e ao que se submetem, como signo distintivo, os membros do "grupo noigandres" - Haroldo e Augusto de Campos e Décio Pignatari -, responde tanto à banalização de uma herança viva por parte da geração de 45, como a uma "rigorização" dos postulados mais ambiciosos do inseminador do grupo de 1922.

Foram três, segundo meu ponto de vista, os maiores resultados da intervenção da poesia concreta no cenário da literatura brasileira contemporânea. Já me referi a dois deles: por um lado, ter restaurado, sob a égide do "pai

14. ver nota 2.

15. Ver Haroldo de Campos: "De la razón antropofágica". México, Vueltan. 68, 1982. 
antropófago" Oswald de Andrade, o espírito da vanguarda dos anos 1920, apesar da miopia da geração de 45 que a tomava como uma referência histórica, porém já sem considerá-la uma sensibilidade atuante. Por outro lado, a partir da abertura de referências e da revisão da noção ontológica de nacionalismo literário, que, naquele momento como hoje, ameaçava com o encerramento e a autogratificação populista à livre iniciativa intelectual, ter enfrentado o debate ideológico central da cultura brasileira dos anos 1950, de oposição vanguarda-subdesenvolvimento.

Em relação a ela, os poetas concretos defenderam o risco da criação artística frente ao policiamento ideológico de certas tendências engagées como o neo-concretismo, liderado por Ferreira Gullar no Rio de Janeiro, movimento marcado pela preocupação de adequar o discurso poético às limitações da realidade social. Assim, a intervenção dos poetas concretos no panorama cultural brasileiro colocou entre aspas o debate vanguarda-subdesenvolvimento, demonstrando o viés eminentemente subdesenvolvido, ou simplesmente falso, desta problemática paralisante.

O terceiro grande mérito do movimento da poesia concreta foi ter sabido garantir o trânsito, através da sua própria evolução, entre esse espírito de restauração crítica da vanguarda e o momento subseqüente, que se vive no Brasil atual. Se considerarmos a posição do concretismo "heróico" como "pós-modernista", como disse anteriormente, a auto-superação da poesia concreta, superação que se diferencia nas obras de cada um dos membros fundadores do movimento, nos permite ver essa evolução como a forma mais evidente de acesso, no Brasil, à "pós-modernidade" - conceito que uso aqui numa acepção principalmente de geração, o que, portanto, exclui a problemática dos traços semânticos, ou mesmo epistemológicos, que essa noção difusa e discutível tem assumido nos últimos anos.

Como disse no começo deste ensaio, coube à geração da poesia concreta e, em especial, ao crítico mais articulado entre seus membros, Haroldo de Campos, reeditar, no contexto da cultura brasileira atual, as duas posições que definiram historicamente as atuações das duas primeiras gerações posteriores a 1922, a modernista de Mário e Oswald de Andrade, e a moderna de Drummond e Murilo Mendes. Essa capacidade de evoluir internamente, que não deixa de lado nem o espírito crítico nem o impulso criador que tinham caracterizado a sua produção dos anos 50, além de não se travestir com um discurso dominado pela perplexidade e o desencantamento, indica que no trânsito da vanguarda à pós-vanguarda - ou, se quisermos, da postura "utópica" à "pós- 
utópica", para ficarmos com outra terminologia do próprio poeta -, do momento pós-modernista ao pós-moderno (termo que aqui uso com as restrições apontadas), a cultura brasileira chega à maturidade plena, na qual o vetor vanguarda afirma-se, de maneira tangencial, como o mais importante em seu crescimento orgânico.

A resistência de boa parte da crítica de poesia no Brasil em considerar, no seu julgamento sobre o significado da vanguarda brasileira em nossa vida intelectual, a capacidade transformadora dessa corrente, só é comparável à sua obstinação em analisar as vanguardas a partir de esquemas interpretativos prédeterminados, ou com o deturpador critério sociológico, ou pelo puro preconceito antivanguardista. Um ou outro caso não esconde a incapacidade de setores da nossa intelligentisia de conseguir formalizar projetos tão abrangentes, tão resistentes ao exame do tempo, e, por isso mesmo, intelectualmente tão promissores, como o derivado, por exemplo, da poesia concreta. Reduzir a obra dos integrantes do "grupo noigandres" à sua produção dos anos 50, reduzir sua participação na cultura brasileira à transcendência que teve, no seu momento, o "plano piloto para a poesia concreta" (1958), que lido e avaliado com os olhos de hoje apresenta sinais evidentes de uma flamante inocência programática, é, além de lhes negar os não poucos sinais de vitalidade que se foram demonstrando ao longo dos últimos anos, abraçar uma visão congelada do processo histórico-literário nacional e se recusar a considerar o que nele mudou, em termos éticos, para não falar em termos estéticos, entre os anos 1930 e os que estamos vivendo. ${ }^{16}$

O papel de Haroldo de Campos, o mais clarividente e articulado entre os participantes dessa vanguarda histórica, foi fundamental nesse quadro evolutivo. Foge ao âmbito deste ensaio focalizar, com o detalhamento que merece, as marcas dessa evolução no contexto da sua produção como ensaísta e tradutor. No entanto, desejo me referir a dois aspectos inter-relacionados que indicam sua dinâmica no seio da cultura brasileira contemporânea.

\footnotetext{
16. Nesse sentido, coincido com Eduardo Milán no seu "Prólogo a una poesía sin prólogos" (in Transideraciones / Transiderações, antologia bilíngüe da obra poética de Haroldo de Campos; organizada e traduzida por Eduardo Milán e por Manuel Ulacia; México, El Tucán, 1987), onde o crítico uruguaio diz: "Já que a poesia concreta na sua etapa ortodoxa (...) obrigou seus criadores a uma prática quase anônima pela necessidade de coletivização do poema, a crítica preferiu fixar os poetas concretos na sua etapa 'de guerra' e deixá-los morrer naquela instância de sua produção, como se aquele tivesse sido seu último suspiro. Essa foi uma das mais hábeis jogadas da crítica tradicional de poesia no Brasil, já que essa imagem se espalhou pela América Latina." (p. 9)
} 
O primeiro deles se refere diretamente ao valor de logodescentralização que apontei anteriormente. Está ligado à transformação do que poderia se considerar uma noção estática ou redutora da poesia concreta, circunscrita no tempo e sustentada no rompimento do suporte verso-linear em favor da articulação poética verbivocovisual, em uma noção dinâmica, que procura reconhecer, por essa mesma razão, a incidência daquilo que seria a "concretude" poética em autores e épocas distantes no tempo e no discurso, como Dante, Gœthe ou os poetas russos modernos, todos eles traduzidos por Haroldo de Campos. Em relação ao acervo literário nacional, o resgate de escritores como Pedro Kilkerry e Sousândrade, poetas "raros" do século XIX brasileiro cujas obras foram recicladas por Augusto e Haroldo de Campos na década dos 70, aponta no mesmo sentido de abertura da noção estática da poesia concreta através da invenção, da absorção, da dinamização de um novo canon afinado com suas premissas estéticas.

A transformação da poesia concreta de algo "exclusivo" em algo "inclusivo" - de momento em sistema, tal como disse antes em relação ao papel da geração de 1930 vis-à-vis aos modernistas "heróicos" - é o que se apresenta neste gesto: ao tentar estabilizar um movimento de ruptura através da eleição-interpretação de uma certa tradição, transforma-se o que poderia ter-se limitado a uma forma circunstancial, vinculada a um momento histórico e intelectual preciso, em uma poética. ${ }^{17}$ Mesmo que um processo como este não seja exclusivo da literatura brasileira contemporânea, já que, como sabemos, a "invenção de uma tradição" é um dos mecanismos mais característicos dos movimentos artísticos modernos, no contexto esse processo foi e ainda é central para compreender a pluralidade de referentes em nossa vida intelectual atual.

$\mathrm{Na}$ "Tese VI" sobre a filosofia da história, Benjamin resume da seguinte maneira todo o complexo mecanismo de re-interpretação do acervo histórico: "To

17. Em relação a isto, ver o prefácio de Andrés Sánchez-Robayna à edição espanhola bilíngüe de A educação dos cinco sentidos (La educación de los cinco sentidos, Barcelona, àmbit, 1990; tradução, prólogo e notas de Andrés SánchezRobayna), onde o escritor espanhol diz: "Com efeito, desde cedo os poetas concretos se propuseram uma 'retroação' teórica na sua concepção da linguagem. Os princípios de economia, medularidad, escencialidade, fragmentação, metalinguagem, são rigorosamente investigados na poesia do passado. Esses estudos descobriram que não só pode se fazer uma 'história' da atitude concreta desde Homero, mas que, de fato, são os poetas mais atentos à materialidade do signo aqueles que representaram verdadeiros hitos na história da linguagem da poesia." (p. 14) 
articulate the past historically does not mean to recognize 'the way it really was' (...). It means to seize hold of a memory as it flashes up in a moment of danger". Em seu processo de auto-estabilização, feito a partir de um exercício real de interpretação do "arquivo" literário jacente, o "perigo" contra o qual combateu a poesia concreta foi a concepção da história em geral, e da história literária em particular, como uma cidade ideal na qual não se localizariam as exceções à sua bem planejada concepção. Aqui, trata-se da substituição de macrocategorias historiográfico-estéticas (Romantismo, Simbolismo, Barroco...) por uma noção de "séries literárias" nas quais os elementos constitutivos evidenciam sinais de mutualidade e se estendem organicamente ao longo da história. Ao pôr em xeque os lugares comuns da historiografia e reivindicar a inserção da cultura brasileira num amplo leque de referências multiculturais, a intervenção logo-descentralizadora da poesia concreta, e especialmente de Haroldo de Campos, revela-se também como democratizante, no sentido de que refuta uma interpretação oficializada e redutora da cultura brasileira ou, o que seria talvez mais perigoso, dos grandes paradigmas da cultura ocidental a partir do Brasil.

Se neste processo de sincronização seriada está em jogo assumir uma linhagem de "afinidades eletivas" com o acervo internacional ou nacional, um segundo aspecto, relacionado com o anterior e não menos significativo, pode ser percebido na crescente importância que o estudo e a apropriação do barroco ganham na obra de Haroldo de Campos, com reflexos de maneira natural num barroquismo cuidadosamente trabalhado em sua escrita poética. Antes de me referir apenas ao nível mais óbvio da exploração das possibilidades visuais ou combinatórias da palavra poética, o que aproxima a retórica à poesia concreta do Barroco histórico (aproximação já explorada por mim em um outro ensaio $^{19}$ ), e que corresponde, na obra de Haroldo de Campos, a poemas emblemáticos como "fome de forma" e "nascemorre" ambos de fome de forma (1959), agora me interessa enfatizar o papel do barroco na sua produção poética mais "convencional", ou seja, textual-linear.

Primeiramente, tem que ficar claro que, em Haroldo de Campos, a relação com a estética barroca não se opõe ao princípio vetor de toda a sua obra, o da obediência ao rigor compositivo e intelectual. ${ }^{20}$ Já em 1952, o poeta,

18. Walter Benjamin: Illuminations. Ensaios editados e traduzidos por Hannah Arendt. Nova Iorque, Schocken Books, 1969; "Theses on the philosophy of history", p. 253-267; cit. p. 255. 
falando como se fosse seu próprio Mestre, anunciou em "Ciropedia ou a educação do príncipe" sua submissão a esse princípio ("Na hora dos deméritos o Mestre diz: Rigor"). Por sua vez, em "Teoria e prática do poema" (do mesmo ano), Haroldo se refere à autogênese da palavra poética nos termos líricos e rigorosos que seguem:

\author{
mesurado geômetra \\ o poema se pensa \\ como um círculo se pensa em seu centro \\ como os raios do círculo o pensam \\ fulcro de cristal do movimento \\ O poema se propõe: sistema \\ de premissas rancorosas, \\ evolução de figuras contra o vento \\ xadrez de estrelas. (...)
}

Entre a "mesurada geometria" que o poema não só significa, mas que também incorpora na sua forma, e o "vento xadrez de estrelas", referência a uma passagem do "Sermão da sexagésima" do autor barroco por antonomásia da língua portuguesa, Padre Antonio Vieira (1608-1697), equilibram-se in nuce os dois pólos da dicção haroldiana. Esta fusão, em si mallarmeana, entre a palavra esqueleto e a palavra disseminação, entre cristal e essência, responde tanto pela experiência escritural de Galáxias, como por momentos que encapsulam tudo o que disse neste ensaio.

Por exemplo, em "Minima moralia" (de A educação dos cinco sentidos, 1985), ao reduzidíssimo suporte de referências corresponde uma vasta rentabilidade intertextual, procedimento em si mesmo quintessencialmente barroco:

já fiz de tudo com as palavras

agora quero fazer de nada

19. Ver "La poesía visual brasileña", Madrid, Cuadernos Hispanoamericanos N0 495 (Septiembre de 1991), p. 53-78.

20. Vale a pena recordar que, já em 1955, Augusto de Campos disse sobre a escrita de seu irmão: "Haroldo de Campos é, por assim dizer, um 'concreto' barroco o que faz que ele trabalhe preferencialmente com imagens e metáforas, que dispõe em verdadeiros blocos sonoros." (in "Da poesia concreta a Galáxias e Finismundo: quarenta anos de atividade poética no Brasil”, cit.) 
Este pequeno poema, que lembra tanto o Adorno de Minima Moralia, quanto o poema-piada cunhado por Oswald de Andrade, em suas duas breves linhas, guarda subjacente a superfície textual que remete tanto ao aforismo quanto ao haicai o trânsito de Haroldo de Campos da vanguarda à pós-vanguarda, da utopia do projeto autonutriente à pós-utopia que se nutre da experiência do devir: humor, ironia, claridade de quem soube se converter em seu próprio herdeiro e se observa a si mesmo sob o prisma da conciliação.

Como vimos ao longo deste ensaio, esta faceta ética vai além da dinâmica da localização da linhagem de Haroldo de Campos na literatura brasileira contemporânea, ponte entre dois momentos. Esta faceta se apresenta não apenas como uma direção de produção textual na sua obra, através da coabitação que nela percebemos, entre os vetores do rigor minimalizante e a disseminação barroca, mas também como uma característica temperamental de um poeta-ideólogo que, sem abdicar da sua própria trajetória, encontra-se aberto aos ventos, não elíseos, sempre complexos, tão complexos, da história atual.

Cidade do México, junho de 1991. Tradução: Graciela Foglia e Rômulo Monte Alto - UFMG

Abstract: Review of Haroldo de Campos' trajectory through the concrete poetry and the nacional culture. Key words: Haroldo de Campos, Brazilian culture. 